\title{
Kit formulation of active pharmaceutical ingredient d,I-HMPAO as a brain perfusion diagnostic system
}

\section{Mohammadreza Davarpanah, Hossein Abbasi, Mehdi Nabati*, Hamideh Sabahnoo, Vida Bodaghi-Namileh, Mohammad Mazidi, Hossein Movahhed-Tazehkand, Hossein Mohammadnejad-Mehrabani}

Synthesis and Molecular Simulation Laboratory, Chemistry Department, Pars Isotope Company, P.O. Box: 1437663181, Tehran, Iran

\section{ART ICLE I N F O}

\section{Article history:}

Submitted: 2019-09-26

Revised: 2019-10-19

Accepted: 2019-11-01

Available online: 2019-11-08

Manuscript ID: PCBR-1909-1062

\section{KEY Y O R D S}

Exametazime HMPAO

Kit Formulation

Nuclear medicine

Radiopharmaceutical

Technetium-99m

radionuclide

\section{GRA P H I C A L A B S T RACT}

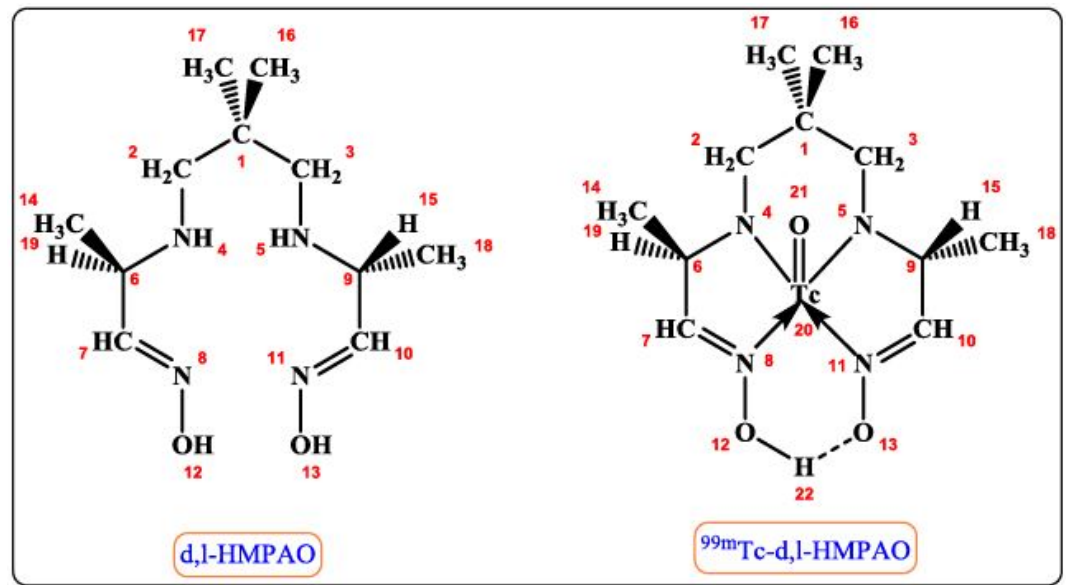

A B S T R A C T

The purpose of this research study is to prepare exametazime (d,l-HMPAO) kit for labeling with $99 \mathrm{~m}$-technetium radionuclide as a brain perfusion diagnostic system. Firstly, the active pharmaceutical ingredient d,l-HMPAO was prepared in two steps with the purity of $99.29 \%$. Its molecular structure was characterized using elemental analysis, Fourier-transform infrared spectroscopy (FT-IR), and nuclear magnetic resonance (NMR) technique. In second step, the d,l-HMPAO kit was prepared using six different formulations and labeled by technetium-99m radionuclide. The high radiochemical yield was attributed to the high amount of $\mathrm{SnCl}_{2}$ and adding phosphate buffer. The animal studies were conducted on the three-month old male Wistar rats. The results of the biodistribution studies revealed that, the mean activity in brain of all rats was above $1 \% \mathrm{ID} / \mathrm{g}$. This showed the high isomerism purity of the synthesized compound (d,l-HMPAO) and optimization of the suggested formulations. 


\section{Introduction}

Exametazime which is mainly known by its chemical name hexamethylpropyleneamine-oxime or HMPAO has been used as a chelating agent to bind with technetium-99m [1]. Technetium-99m ( ${ }^{99 \mathrm{~m} T c)}$ is an isotope of technetium99 and a gamma-emitter agent utilized in various fields of diagnostic medicine. In addition, based on its favorable qualities, $99 \mathrm{mTc}$ is one of the most investigated radioisotopes in nuclear research areas [2]. The HMPAO ligand comprises of two diastereomeric isoforms are including d,l-HMPAO and meso-HMPAO []] HMPAO is a well-established radiotracer in cerebral imaging and leukocytes labeling for detection of several infectious and inflammatory diseases $[\underline{4}, \underline{5}]$. ${ }^{99 m T c-d, l-}$ HMPAO is the first $99 \mathrm{mTc}$-labeled tracer used for evaluating the regional cerebral blood (rCBF) [6-10]. Regional cerebral blood flow represents the amount of blow flow to a specific region of the brain in a predetermined time [11]. Considering the fact that various pathological processes in the brain originate from alterations in cerebral blood perfusion, the diagnostic capabilities of $99 \mathrm{~m}$ Tc-d,l- HMPAO is of particular importance in early detection of neurocognitive disorders such as schizophrenia [12], major depressive disorder [13], epilepsy [14], migraine [15], meningioma [16], and Alzheimer's[17]. 99mTc-d,l- HMPAO SPECT (single-photon emission computed tomography) is considered to be one of the most reliable scintographic studies and imaging methods in early diagnosis of dementia[18]. Due to its lipophilic nature, $99 \mathrm{mTc}$-d,l-HMPAO readily permeates through blood-brain barrier (BBB) and converts into hydrophilic species incapable of back-diffusion thus guaranteeing entrapment of the agent in brain cells. Within one minute after the injection of $99 \mathrm{mTc}-\mathrm{d}, \mathrm{l}-$ HMPAO, a maximum of $3.5-7.0 \%$ of the injected dose is up-taken into the brain although up to $15 \%$ of the activity is lost after about only $2 \min$ [19-21]. The objective of the current study was to introduce a novel route for the synthesis of the active pharmaceutical ingredient (d,lHMPAO) for the preparation of $99 \mathrm{mTc}-\mathrm{d}, \mathrm{l}-\mathrm{HMPAO}$ radiopharmaceutical. In addition, different kit formulations were suggested, with minor alterations in previously investigated formulations, and further analyzed to reach two optimum formulations with the best observed results. Due to the inherent instability of 99mTc-d,l-HMPAO and its spontaneously degradation into hydrophilic agents, quality control measures were carried out in a span of 5 to $30 \mathrm{~min}$ after labeling procedure. Furthermore, to gain a better insight into this radiopharmaceutical's behavior and function in vivo, animal studies were conducted and regional brain perfusion was investigated in Wistar rats. Moreover, the amounts of liver and kidney uptake were measured as indicators of metabolism and elimination, respectively.

\section{Experimental}

\subsection{Materials and Methods}

2,3-Butanedione monoxime, $\mathrm{KHPO}_{4}, \mathrm{KH}_{2} \mathrm{PO}_{4}$, tin (II)chloride dehydrate, tin (II) fluoride and ethyl acetate was purchased from Sigma-Aldrich (St. Louis, MO, USA). The

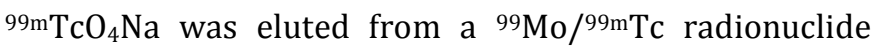
generator (Pars Isotope, Tehran, Iran). Ethanol, 2,2dimethyl-1,3-propanediamine, para-toluene sulfonic acid monohydrate, benzene, sodium hydroxide, sodium chloride, sodium borohydride, acetic acid, acetonitrile and methyl ethyl ketone was obtained from Merck (Darmstadt, Germany). Distribution of the radioactivity on the chromatography papers were quantified using a Lablogic mini scan TLC scanner (Sheffield, UK) and analyzed with Lura image analysis software.

\subsection{Optimized synthesis and characterization of $d, l-$ HMPAO}

Scheme 1 shows the molecular structure of active pharmaceutical ingredient d,l-HMPAO. In our previous study, we discussed the reactivity and stability of the d,lHMPAO and its complex with 99m-technetium 
radionuclide [22]. In this work, we synthesized this medicinal compound in two steps. Firstly, $73 \mathrm{~g}$ of 2,3Butanedione monoxime, $0.2 \mathrm{~g}$ of para-toluene sulfonic acid monohydrate and $750 \mathrm{~mL}$ of benzene were added to a 2 L round-bottomed flask equipped with a Dean-Stark trap. The reaction mixture was heated $\left(85{ }^{\circ} \mathrm{C}\right)$ and normally stirred for $2 \mathrm{~h}$. The reflux process was continued until the solid was completely dissolved. Then, $60 \mathrm{~g}$ of 2,2dimethyl-1,3-propanediamine was dissolved in $100 \mathrm{~mL}$ of benzene. This solution was added dropwise into the flask. The reaction mixture was refluxed for $20 \mathrm{~h}$. Then, the yellow colored solution was stirred for $24 \mathrm{~h}$ at $4{ }^{\circ} \mathrm{C}$. The white solid formed was collected by Buckner filtration, washed with cold acetonitrile four times (each time with $250 \mathrm{~mL}$ of solvent). The white solid compound was dried under the vacuum over calcium chloride. $96.8 \mathrm{~g}$ of this compound was obtained. In second step, $96 \mathrm{~g}$ of the white solid compound and $930 \mathrm{~mL}$ of absolute ethanol were added in a $2 \mathrm{~L}$ round-bottomed flask and stirred in an ice bath. Then, $20.4 \mathrm{~g}$ of sodium borohydride $\left(\mathrm{NaBH}_{4}\right)$ was gradually added to the reaction mixture over a period of 2 h. After adding sodium borohydride, the reaction mixture was stirred for $3 \mathrm{~h}$. After this time, $290 \mathrm{~mL}$ of deionized water was added into the flask. The reaction mixture was stirred for 1 hour at $0-5{ }^{\circ} \mathrm{C}$. Then, $92.52 \mathrm{~mL}$ of acetic acid was added dropwise to the flask. The reaction mixture was then warmed to room temperature and stirred overnight. The next day, ethanol was removed under vacuum. Then, the $\mathrm{pH}$ of the residual slurry was adjusted to 11 and was kept overnight at $4{ }^{\circ} \mathrm{C}$ to complete the precipitation. After $24 \mathrm{~h}$, the white precipitation was collected by Buckner filtration and washed with $4 \mathrm{~L}$ of cold deionized water and dried under vacuum over calcium chloride. This white solid compound is a mixture of d,l-HMPAO and meso-HMPAO. We isolated the d,lHMPAO isomer from the meso-HMPAO isomer using acetonitrile and ethyl acetate solvents. The isomers mixture was treated with $400 \mathrm{~mL}$ hot acetonitrile under severely magnetic stirring. Then, it was filtered and the solute was kept in refrigerator for three days. The white precipitated compound was filtered and dissolved in 400 $\mathrm{mL}$ of hot ethyl acetate. The solution was filtered and the solute kept in refrigerator for three days. The white compound was collected and dissolved in $400 \mathrm{~mL}$ of acetonitrile again. The solution was filtered and the solute kept for another three days in refrigerator. Finally, the white product was collected and died under vacuum over calcium chloride. The yield of the final compound was 5.1 g.

\section{Scheme 1. Molecular structure of d,l-HMPAO}

\section{Evaluation of d,l-HMPAO Kit Formulation}

As seen in Table 1, five alternative formulations A-E were prepared by changing the affected parameters in radiochemical yield including, the amounts of $\mathrm{SnCl}_{2}$, percentage of solvent ethanol, $\mathrm{pH}$ and stabilizer agents (such as phosphate buffer).

For radiolabeling, to any formulations, we added a sodium

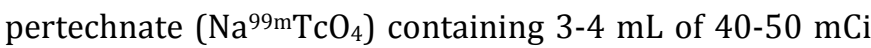
of $99 \mathrm{~m} \mathrm{TcO}_{4}$. The reaction was incubated at room temperature for $30 \mathrm{~min}$. Then the radiochemical yield was determined using the ITLC-SG and Whatman ET31 chromatography papers in different mobile phases such as normal saline, mixture of (saline and acetonitrile) and Methyl Ethyl Ketone (MEK). In TLC, when normal saline was used as mobile phase, free ${ }^{99} \mathrm{~m} \mathrm{TcO}_{4}{ }^{-}$and $99 \mathrm{~m} \mathrm{Tc}-$ HMPAO-secondary migrate to the solvent front $(\mathrm{Rf}=1.0)$, while ${ }^{99 \mathrm{~m} T c-H M P A O}$ lipophilic and colloid remain at the application point $(\mathrm{Rf}=0.0)$. However, for MEK system the colloids and secondary remain near the point of spotting $(\mathrm{Rf}=0.0-0.3)$ and 99mTc-HMPAO lipophilic and free $99 \mathrm{mcO}_{4}^{-}$moved towards the solvent front. In mixture of saline and acetonitrile (1:1) only colloid remains at the 
application point and other radiolabeled complex moved towards. Radiolabeling yield of the kits was determined using TLC at $30 \mathrm{~min}$.

In the same condition of kit formulations, high radiochemical yield was accepted by adjusting $\mathrm{pH}$ in range 9-9.30 (compare to formulation A and B). Optimum formulation was determined by adding less percentage of solvent ethanol (formulation $\mathrm{C}$ ). The amount of ethanol present would make it unstable for radiolabeling. However, high radiochemical yield was accepted by using high amount of $\mathrm{SnCl}_{2}$ and adding phosphate buffer (formulation D).

\section{Animal Studies}

Three-month old male Wistar rats weighing 150-200 g were acquired from the Animal House, Pars Isotope Company, Tehran, Iran. The animals were housed in standard laboratory conditions $\left(20 \pm 5^{\circ} \mathrm{C}\right.$ and $14 \mathrm{~h}$ dark$10 \mathrm{~h}$ light cycle) and provided with water and standard diet. The animals were allocated into 2 equal groups of 6 rats, each receiving $100 \mathrm{mCi}$ of 99m-Tc-l,d-HMPAO injections through the animal's tail vein. One hour after administration all rats were anesthetized by xylidine and further euthanized. Afterwards, the rats' organs were immediately extracted and weighed. To measure the tracer's uptake by different organs, a standard gamma counter was utilized and related results were reported by percentage injected dose per gram (\%ID/g) of tissue and percentage injected dose per organ (\%ID/organ), 1 and $10 \mathrm{~min}$ after injection. The 99m-Tc-l,d-HMPAO 1 and 10 min biodistribution results are presented in Table 1 . As presented in Table 1, the mean activity in brain of all rats reached above 1\% ID/g, indicating complete purity of synthesized isomer and optimization of the suggested formulations. Moreover, the high mean counts in liver suggests hepatic metabolism of the investigated agent.

\section{Results and Discussion}

\subsection{Characterization of d,l-HMPAO}

The purity of the d,l-HMPAO was gained by HPLC using a $\mu$-Porasil normal phase column, with a UV $210 \mathrm{~nm}$ detector, with methanol:0.4M NH4OH (95:5) as the mobile phase at a flow rate of $1 \mathrm{~mL} / \mathrm{min}$. In this system, there is a difference of $1 \mathrm{~min}$ between the retention times of the d,lHMPAO and the meso-HMPAO. The HPLC analysis showed $\% 99.29$ for this isomer (d,l-HMPAO).

Melting point of $\mathrm{d}, \mathrm{l}-\mathrm{HMPAO}$ isomer: $133^{\circ} \mathrm{C}$.

Table 1. Condition of optimum formulation of $99 \mathrm{mTc}-\mathrm{HMPAO}$ complex

\begin{tabular}{|c|c|c|c|c|c|c|c|}
\hline Formulation & $\begin{array}{c}\text { HMPAO } \\
\text { (mg) }\end{array}$ & $\begin{array}{c}\mathrm{SnCl}_{2} \\
(\mu \mathrm{g})\end{array}$ & $\begin{array}{l}\mathrm{NaCl} \\
(\mathrm{mg})\end{array}$ & $\begin{array}{c}\text { EtOH } \\
\%(V / V) \\
\text { Solvent }\end{array}$ & Buffer & $\mathrm{pH}$ & $\begin{array}{c}\% \\
\text { (Labeling } \\
\text { Yield) } \\
30 \text { min }\end{array}$ \\
\hline A & 0.5 & 8 & 4.5 & 10 & - & $9-9.5$ & 80 \\
\hline B & 0.5 & 8 & 4.5 & 10 & - & $7.5-8$ & 30 \\
\hline C & 0.5 & 8 & 4.5 & 4 & - & $9-9.5$ & 97 \\
\hline D & 0.5 & 13.5 & 4.5 & 4 & phosphate & $9-9.5$ & 97 \\
\hline $\mathrm{E}$ & 0.5 & 7.6 & 4.5 & 4 & - & $9-9.5$ & 92 \\
\hline $\mathrm{F}$ & 0.5 & $\begin{array}{c}6.3 \\
\left(\mathrm{SnF}_{2}\right)\end{array}$ & 4.5 & 4 & - & $9-9.5$ & 92 \\
\hline
\end{tabular}


Table 2. Biodistribution of ${ }^{99 \mathrm{~m}} \mathrm{Tc}-\mathrm{d}, \mathrm{l}-\mathrm{HMPAO}$ in male Wistar rats

\begin{tabular}{cccccccc}
\hline \multirow{2}{*}{ Biodistribution } & \multirow{2}{*}{ Time (min) } & Brain & Blood & Liver & Kidney & Stomach & Intestine \\
& & & & & & & \\
\hline & 1 & $1.74 \pm 0.06$ & $8.46 \pm 2.79$ & $20.32 \pm 1.91$ & $3.90 \pm 0.11$ & $1.92 \pm 0.32$ & $15.87 \pm 0.79$ \\
Mean Count & 10 & $0.40 \pm 0.01$ & $9.13 \pm 0.96$ & $22.66 \pm 1.58$ & $3.15 \pm 0.12$ & $0.89 \pm 0.55$ & $16.85 \pm 1.17$
\end{tabular}

Elemental analysis: C (\% 57.82), H (\% 10.11) and N (\% 20.96).

FT-IR (KBr, v cm${ }^{-1}$ ): 1488, 1533, 1654, 1705, 1863, 2919, 2931, 2956, 2987, 2992, 3023, 3030, 3036, 3088, 3111, 3129, 3150-3450.

${ }^{1} \mathrm{H}-\mathrm{NMR}$ (CD3OD, $\left.500 \mathrm{MHz}, \delta \mathrm{ppm}\right): 0.99$ (s, 6H, gem- $\left.\mathrm{CH}_{3}\right)$, $1.17\left(\mathrm{~d}, 6 \mathrm{H}, \mathrm{NH}-\mathrm{CH}-\mathrm{CH}_{3}\right), 2.98\left(\mathrm{~s}, 6 \mathrm{H}, \mathrm{HON}=\mathrm{C}-\mathrm{CH}_{3}\right), 2.41$ $\left(4 \mathrm{H}, \mathrm{CH}_{2} \mathrm{NH}\right)$ and $2.86\left(\mathrm{q}, 2 \mathrm{H}, \mathrm{NHCH}-\mathrm{CH}_{3}\right)$. ${ }^{13} \mathrm{C}-\mathrm{NMR}$ (proton decoupled) (CD3OD, $\left.500 \mathrm{MHz}, \delta \mathrm{ppm}\right)$ : $13.2,15.5,23.5,33.6,43.2,59.7$ and 164.6.

\subsection{Results of the d,l-HMPAO Kit Formulations}

Previously a reported formulation kit of HMPAO was as a formulation $\mathrm{E}$ (Ceretec ${ }^{\mathrm{TM}}$ kit) but results revealed a decrease in the [99m Tc] Tc-D,L-HMPAO radiochemical yield (increasing 99mTc-HMPAO-secondary), $30 \mathrm{~min}$ from kit reconstitution. In our survey, a lipophilic compound is decomposed due to molecular structure instability, high radiation doses, $\mathrm{SnCl}_{2}$ excess and high $\mathrm{pH}$. For above reasons, we explored effect of $\mathrm{pH}$, buffer, $\mathrm{SnCl}_{2}$ amount and solvent on the stability of [99mTc] Tc-D, L-HMPAO. In the same condition of kit formulations, high radiochemical yield was accepted by adjusting $\mathrm{pH}$ between 9 and 9.30 (compare to formulation A and B). Optimum formulation was determined by adding less percentage of solvent Ethanol (formulation C). The amount of EtOH present would make it unstable for radiolabeling. However, high radiochemical yield was accepted by using high amount of $\mathrm{SnCl} 2$ and adding phosphate buffer (formulation D). As the rate of decomposition of the lipophilic complex increased at the presence of excess stannous Sn (II) ion, the amount of stannous chloride in the kit became very low. For using high amount of stannous chloride (for strong labeling), we added pH-adjusting agent and free radical scavenger (phosphate buffer) to oxidize excess $\mathrm{Sn}$ (II) ion remaining after labeling. At the formulation $\mathrm{F}$, we used stannous fluoride instead of stannous chloride as reducing agent. There were two reasons for this: different coordination chemistry with $\mathrm{N}$ - or $\mathrm{O}$-donor ligands and different reaction in ethanol with those ligands. Unexpectedly, results (comparison between formulation E and F) revealed that, radiochemical yield was same at different formulations.

\section{Conclusions}

This work aimed at preparation of d,l-HMPAO kit for labeling with $99 \mathrm{~m}$-technetium radionuclide as a brain perfusion diagnostic system. Synthesis and preparation of the active compound d,l-HMPAO (exametazime) was carried out at two steps. The prepared active pharmaceutical ingredient was purified using solventantisolvent purification method and characterized by spectroscopy techniques. The purity of the synthesized active substance was above 99 percent. In second step, the d,l-HMPAO kit was prepared using different formulations and labeled by $99 \mathrm{~m}$-technetium radionuclide. The formulation containing high amount of $\mathrm{SnCl}_{2}$ and adding phosphate buffer showed the high radiochemical yield. It 
was found that, the mean activity in brain of all rats was above $1 \%$ ID/g. This indicated complete purity of the synthesized isomer (d,l-HMPAO) and optimization of the suggested formulations.

\section{Conflict of Interests}

The authors declare that there is no conflict of interests regarding the publication of this paper.

\section{References}

[1] L. Uccelli, P. Martini, M. Pasquali and A. Boschi, Radiochemical purity and stability of $99 \mathrm{~m} \mathrm{Tc-}$ HMPAO in routine preparations. Journal of Radioanalytical and Nuclear Chemistry, 314 (2017) 1177-1181.

[2] S.M. Rathmann, Z. Ahmad, S. Slikboer, H.A. Bilton, D.P. Snider and J.F. Valliant, The Radiopharmaceutical Chemistry of Technetium-99m, in Radiopharmaceutical Chemistry. (2019), Springer. 311-333.

[3] J. Pijarowska-Kruszyna, U. Karczmarczyk, A.W. Jaroń, E. Laszuk, M. Radzik, P. Garnuszek and R. Mikołajczak, New synthesis route of active substance d, 1-HMPAO for preparation Technetium Tc99m Exametazime. Nuclear Medicine Review, 20 (2017) 88-94.

[4] D. Chroustová, N. El-Lababidi, J. Trnka, L. Černa and L. Lambert, Scintigraphy with 99mTc-HMPAO labeled leukocytes is still an accurate and convenient tool to rule out suspected inflammatory bowel disease in children. Nuclear Medicine Review, 22 (2019) 6973.

[5] S. Auletta, V. Iodice, F. Galli, N. Lepareur, A. Devillers and A. Signore, Study of Binding Kinetics and Specificity of $99 \mathrm{mTc}-\mathrm{SSS}-$ Complex and $99 \mathrm{mTc}-$ HMPAO to Blood Cells. Contrast media \& molecular imaging, 2018 (2018)

[6] C. Suzuki, S. Kimura, M. Kosugi and Y. Magata, Quantitation of rat cerebral blood flow using 99mTcHMPAO. Nuclear medicine and biology, 47 (2017) 19-22.

[7] S.M.d.A. Giorgio, M.G. Caprio, F. Galante, G. Russo, A. Romano, E. Vergara, M. Alessio and A. Cuocolo, Clinical Value of Perfusion Abnormalities of Brain on Technetium-99m HMPAO Single-Photon Emission Computed Tomography in Children With Sydenham Chorea. Journal of child neurology, 32 (2017) 316-321.

[8] P. Garrigue, L. Giacomino, C. Bucci, V. Muzio, M.A. Filannino, F. Sabatier, F. Dignat-George, P. Pisano

\section{Acknowledgments}

The authors are grateful to Dr. Fariba Joharidaha, Dr. Nasim Vahidifar and Mr. Farzad Farajbakhsh for providing in valuable support in this research study.

and B. Guillet, Single photon emission computed tomography imaging of cerebral blood flow, bloodbrain barrier disruption, and apoptosis time course after focal cerebral ischemia in rats. International Journal of Stroke, 11 (2016) 117-126.

[9] L. Vlerick, K. Peremans, R. Dockx, K. Audenaert, C. Baeken, J.H. Saunders and I. Polis, The long-term effects of single and repeated subanaesthetic ketamine administration on regional cerebral blood flow in healthy dogs measured with 99mTc-HMPAO SPECT. Psychiatry Research: Neuroimaging, 285 (2019) 18-24.

[10] C. Suzuki, M. Kosugi and Y. Magata, Noninvasive quantitation of rat cerebral blood flow using $99 \mathrm{~m} \mathrm{Tc}-$ HMPAO - assessment of input function with dynamic chest planar imaging. EJNMMI research, 8 (2018) 21.

[11] J. Hodler, G.K. von Schulthess and C.L. Zollikofer, Diseases of the brain, head \& neck, spine 20122015: Diagnostic Imaging and Interventional Techniques. (2012): Springer Science \& Business Media.

[12] M. Jacobsen, A. Jensen, G.B. Storvestre, T.M. Bergstrom, M. Rashi, D. Nori, B. Nielssen, P. Wiktor and K.-E. Hymer, Experiences with 99mTcHMPAO in a diagnostic pathway for violent patients with schizophrenic spectrum disorders. Current radiopharmaceuticals, 10 (2017) 115-122.

[13] J. Li, Y. Yang, Y. Zhu, L. Zhou, Y. Han, T. Yin, Z. Cheng, G. Zhang, Y. Shen and J. Chen, Towards characterizing the regional cerebral perfusion in evaluating the severity of major depression disorder with SPECT/CT. BMC psychiatry, 18 (2018) 70.

[14] J. Wang and R. Carroll, Nuclear Medicine Imaging in Epilepsy. J Epilepsy, 2 (2015) e105.

[15] V. Mancini, G. Mastria, V. Frantellizzi, P. Troiani, S. Zampatti, S. Carboni, E. Giardina, R. Campopiano, S. Gambardella and F. Turchi, Migrainous Infarction in a Patient With Sporadic Hemiplegic Migraine and Cystic Fibrosis: A 99mTc-HMPAO Brain SPECT 
Study. Headache: The Journal of Head and Face Pain, 59 (2019) 253-258.

[16] Z. Al-Faham, M.A. Kassir, D. Wood and H.R. Balon, Appearance of Meningioma on 99mTc-HMPAO SPECT: Correlation with MRI. Journal of nuclear medicine technology, 44 (2016) 90-91.

[17] S.S.H. Davarani, Z. Rezayati-zad, A. Taheri and N. Rahmatian, Highly selective solid phase extraction and preconcentration of Azathioprine with nanosized imprinted polymer based on multivariate optimization and its trace determination in biological and pharmaceutical samples. Mater Sci Eng C Mater Biol Appl, 71 (2017) 572-583.

[18] O. Solomon, W. Rabiu Saidu Umar, H. Sanusi Wara, A. Sadiq Yakubu, M. Michael Azubuike, M. Asugu Mary and H. Louis, Antiulcerogenic Activity of methanol extract and solvent fractions of Stem Bark of Lannea acida (A. Rich) Against Ethanol-Induced Gastric Mucosal Injury in Albino Rats. Prog. Chem. Biochem. Res., 1 (2018) 29-39.

[19] F. Welz, J.C. Sanders, T. Kuwert, J. Maler, J. Kornhuber and P. Ritt, Absolute SPECT/CT quantification of cerebral uptake of $99 \mathrm{mTc}-\mathrm{HMPAO}$ for patients with neurocognitive disorders. Nuklearmedizin, 55 (2016) 158-165.

[20] N. Nikolov, S. Makeyev, O.Y. Yaroshenko, T. Novikova and M. Globa, Quantitative evaluation of the absolute value of the cerebral blood flow according to the scintigraphic studies with $99 \mathrm{mTc}-\mathrm{HMPAO}$. Наукові вісті Національного технічного університету Украӥни Київський політехнічний інституm, (2017) 61-68.

[21] M. Nabati, Prediction of the structural and spectral properties for L, L-ethylenedicysteine diethylester (EC) and its complex with Technetium-99m radionuclide. Journal of Physical \& Theoretical Chemistry, 14 (2017) 49-61.

[22] M. Nabati, V. Bodaghi-Namileh and S. Sarshar, Molecular Modeling of the antagonist compound esketamine and its molecular docking study with non-competitive N-methyl-D-aspartate (NMDA) receptors NR1, NR2A, NR2B and NR2D. Progress in Chemical and Biochemical Research, 2 (2019) 108-119.

\section{How to cite this manuscript:}

M. Davarpanah, H. Abbasi, M. Nabati, H. Sabahnoo, V. Bodaghi-Namileh, M. Mazidi, H. Movahhed-Tazehkand and $\mathrm{H}$.

Mohammadnejad-Mehrabani, Kit formulation of active pharmaceutical ingredient $d, l-$ HMPAO as a brain perfusion diagnostic system. Progress in Chemical and Biochemical Research, 2 (2019) 185-191.

DOI: 10.33945/SAMI/PCBR.2019.4.4

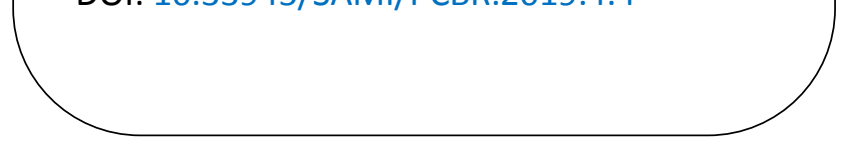

